Onkologie 1996;19:379

\title{
Impressum, Vol. 19, No. 5, 1996
}

\section{Schriftleitung}

W. Queißer, Mannheim H. Huber, Wien

Fachschriftleitung

W. E. Berdel, Berlin E. Dühmke, München R. Hartenstein, München M. Kaufmann, Frankfurt/M. H. Rübben, Essen P. Schlag, Berlin

Wissenschaftlicher Beirat

L. Bergmann, Frankfurt/M.

C. Bokemeyer, Tubingen

U. Creutzig, Münster

V. Diehl, Köln

P. Drings, Heidelberg

L. Edler, Heidelberg

G. Eisenbrand, Kaiserslautern

H. H. Fiebig, Freiburg

H. Gadner, Wien

K. Havemann, Marburg

F. Herrmann, Ulni

R. Herrmann, Basel

D. Hoelzer, Frankfurt/M.

H. J. Illiger, Oldenburg

R. Jakesz, Wien

F. Jänicke, Hamburg

U. R. Kleeberg, Hamburg

R. Kreienberg, Ulm

M. Lehnert, St. Gallen

H. Löffler, Kiel

H. Ludwig, Wien

Chr. Mannhalter, Wien

H. J. Meyer, Hannover FA. Muthny, Münster G. A. Nagel, Freiburg M. Neises, Mannheim R. Parwaresch, Kiel

A. Pfleiderer, Freiburg

M. Pfreundschuh, Homburg/Saar

F. Porzsolt, Ulm

K. Possinger, Berlin H. Samonigg, Graz H. Sauer, München

G. Schackert, Dresden

W. Scheithauer, Wien

H.-J. Schmoll, Halle

R. Schulte-Hermann, Wien S. Seeber, Essen W Siegert, Berlin 
B. Thürlimann, St. Gallen

W Tilgen, Heidelberg

M. Wannenmacher, Heidelberg H. J. Weh, Hamburg Th. Wendt, Jena H. Wilke, Essen M. Wirth, Dresden

Die Zeitschrift erscheint zweimonatlich; pro Jahr erscheint 1 Band zu je 6 Heften.

Bezugspreis für Jahrgang 19,1996, DM 182- I SFr 142,-, einschließlich MwSt., zu-züglich Postgebühren. Der Abonnementpreis ist im voraus zahlbar. Das Abonne-ment der Zeitschrift läuft weiter, wenn es nicht spätestens 4 Wochen vor Abschluß eines Bandes abbestellt wird. Abonnementbestellungen können bei jeder Buchhandlung oder direkt beim Ver-lag aufgegeben werden:

Bundesrepublik Deutschland: S. Karger GmbH, Lörracher Str. 16 a, D-79115 Freiburg, Telefon (0761) 452070, Telefax (0761) 4520714, Postgiro München 40080-807

Übrige Lander: S. Karger AG, Allschwilerstr. 10, Postfach, CH-4009 Basel, Telefon (061)

3061111, Telefax (061) 3061234, E-Mail Karger@Karger.ch.

Anzeigen

S. Karger Verlag für Medizin und Naturwissenschaften GmbH,

Lörracher Str. 16 a, D-79115 Freiburg, Telefon (0761) 452070.

Gültig ist die Preisliste Nr. 9 vom 1. Januar 1996.

Für den Inhalt außerhalb des redaktionellen Teiles (insbesondere Anzeigen, In-

dustrieinformationen, Pressezitate und Kongreßinformationen) übernehmen

Schriftleitung, Beirat und Verlag keine Gewähr.

Eine Markenbezeichnung kann warenzeichenrechtlich geschützt sein, auch wenn

bei ihrer Verwendung in dieser Zeitschrift das Zeichen ( ${ }^{\circledR}$ oder ein anderer Hinweis

auf etwa bestehende Schutzrechte fehlen sollte. Für Satzfehler, insbesondere bei

Dosierungsangaben, wird keine Gewähr übernommen.

Die Zeitschrift sowie alle in ihr enthaltenen einzelnen Beiträge und Abbildungen sind

urheberrechtlich geschützt. Jede Verwertung, die nicht ausdrücklich vom Ur-heberrechtsgesetz zugelassen ist, bedarf der vorherigen Zustimmung des Verlags. Das gilt insbesondere für Vervielfältigungen, Bearbeitungen, Übersetzungen, Mi-kroverfilmungen und die Einspeicherung und Verarbeitung in elektronischen Sy-stemen. Fotokopien dürfen nur für den persönlichen Gebrauch als Einzelkopien hergestellt werden. Jede im Bereich eines gewerblichen Unternehmens zulässig hergestellte oder benutzte Kopie dient gewerblichen Zwecken gem. § 54(2) UrhG und verpflichtet zur Gebührenzahlung an die Verwertungsgesellschaft WORT, Abt. VG Wissensehaft, Goethestraße 49, D-80336 München 2.

(C) Copyright 1996 by S. Karger

Verlag für Medizin und Naturwissenschaften GmbH, Lörracher Str. 16 a

D-79115 Freiburg

Verlagsleitung und presserechtlich verantwortlich: Sibylle Hopf Assistenz: Susanne Meister Herstellung: Georg Brunner Anzeigenverwaltung: Christiane Opitz

Satz und Druck: Walter Biering GmbH Grafischer Betrieb Freisinger Landstraße 21 D-80939

München

KARGER 